\title{
EM DEFESA DO MULTICULTURALISMO: POR UMA PROTEÇÃO PLENA DA LIBERDADE DE RELIGIÃO AOS MUÇULMANOS
}

\author{
DEFENDING MULTICULTURALISM: THE FULL PROTECTION OF RELIGIOUS
} FREEDOM TO MUSLIMS

Mestranda em Direitos Humanos pela UniRitter - Laureate International Universities/RS. Especialista em Direito Público, com ênfase em Direito Administrativo. Graduada em Direito pela UniRitter - Laureate International Universities. Integrante do Grupo de Direito Internacional Crítico.

Tatiana Cardoso Squeff

Professora permanente do Programa de Pós-Graduação em Direito da Universidade Federal de Uberlândia - UFU/MG, onde também atua na graduação. Doutora em Direito Internacional pela Universidade Federal do Rio Grande do Sul - UFRGS, com período de estudos junto à Universityof Ottawa (Canadá). Mestre em Direito Público pela UNISINOS. Coordenadora do Grupo de Direito Internacional Crítico GEPDI/UFU/CNPq.

\begin{abstract}
Resumo
O presente texto tem como essência o debate da questão da liberdade religiosa no âmbito do direito internacional contemporâneo. Logo, apresenta como problema central a violação de direitos humanos e a discriminação de minorias religiosas levada a cabo em Estados onde estão inseridas tais minorias, especialmente a islâmica. Logo, considerando a discriminação e a crescente intolerância para com os muçulmanos na atualidade, busca-se verificar se a liberdade religiosa é, de fato, um direito humano a ser garantido ao indivíduo e como esse problema poderia ser contornado de modo a garantir a plena liberdade de religião aos muçulmanos, o que seria possível através do multiculturalismo, notadamente por ele valorizar a diversidade cultural e fomentar o diálogo intercultural, colaborando para a diminuição da intolerância. Quanto aos aspectos metodológicos, ressalta-se a realização de uma pesquisa de natureza aplicada na área das Ciências Jurídicas e Sociais, onde os objetivos são explorados a partir do método dedutivo, de maneira descritiva e explicativa, baseando-se eminentemente em textos bibliográficos e documentais.
\end{abstract}

Palavras-chave:(In)tolerância. Liberdade Religiosa. Muçulmanos. Multiculturalismo. 


\begin{abstract}
This text has as its essence the debate on the issue of religious freedom in the context of contemporary international law. Therefore, it presents as a central problem the violation of human rights and the discrimination of religious minorities carried out in states where such minorities are inserted, especially the Islamic one. Thus, considering discrimination and growing intolerance towards Muslims in the current world, throught this research it is sought to ascertain whether religious freedom is, in fact, a human right to be guaranteed to the individual and how this problem could be circumvented in order to ensure full freedom. freedom of religion to Muslims, which would be possible through multiculturalism, notably because it values cultural diversity and fosters intercultural dialogue, contributing to the reduction of intolerance. To this end, a monographic study of an applied nature in the area of law is carried out, through which the objectives are exposed from a deductive approach, in a descriptive and exploratory way, mainly adopting the bibliographic and documental procedures.
\end{abstract}

Key-words: (In)tolerance. Multiculturalism. Muslims. Religious Freedom.

\title{
1. CONSIDERAÇÕES INICIAIS
}

O presente escrito tem como essência a questão do direito à liberdade religiosa dos indivíduos - um direito humano fundamental - no âmbito do direito internacional, particularmente a Liberdade dos muçulmanos, voltando-se a questão da liberdade das mulheres muçulmanas em expressar sua religiosidade através do uso dos véus islâmicos - um dos maiores símbolos da religião.

A problemática do tema proposto por esse texto está diretamente ligado a países Ocidentais, pois diversos Estados vem formulando leis domésticas que visam a proibição do uso dos véus islâmicos em locais públicos pelos seguidores da religião islâmica que estão inseridos em suas sociedades e que igualmente compõe o que se pode nomear de minorias religiosas. Assim sendo, questiona-se se a liberdade religiosa é um direito fundamental a ser garantido ao indivíduo considerando a sua constante violação frente à discriminação de muçulmanos na contemporaneidade, e, em sendo um direito fundamental, como poderia ser esse problema contornado na contemporaneidade.

Para encontrar respostas às indagações levantadas, nesse estudo, portanto, tratar-se-á de uma possível ocorrência de violação a direitos humanos advindas do poder estatal. Devido a isso, estipular-se-á, anteriormente, a liberdade religiosa enquanto direito humano tutelado a nível internacional, o qual pode ser, sim, 
considerado enquanto ferramenta passível de promover a paz entre os povos de diferentes culturas se efetivamente respeitado. E, referente a isso, ainda na primeira parte deste texto atentar-se-á a importância do sentimento de (in)tolerância religiosa entre as pessoas, independentemente da sua crença, particularmente em um momento posterior aos atentados de 11 de setembro de 2001 e das tentativas legislativas regionais ocidentais de proibir, em nome da segurança pública, as muçulmanas de expressar sua religiosidade publicamente pela utilização do véu.

Em um segundo momento, como forma de contornar o problema da efetividade do direito humano a liberdade religiosa, adentrar-se-á na discussão acerca do seu fundamento, apresentando-se a possibilidade de interpretar os direitos humanos pelo olhar do multiculturalismo, o qual seria um meio termo entre o universalismo e o relativismo cultural (radical) - teorias consideradas básicas no que pertine a fundamentação dos direitos humanos -, que poderia oferecer uma solução ao segundo questionamento realizado, especialmente porque as nações têm o dever de primar pela plena liberdade dos cidadãos domiciliados em suas jurisdições, o que inclui a liberdade de religião para a garantia plena da dignidade humana de todos (muçulmanos ou não), de modo que a valorização da diversidade cultural, ressaltada através do diálogo intercultural, mostra-se realmente importante.

Quanto aos aspectos metodológicos, pelo presente escrito realiza-se uma pesquisa aplicada na área das Ciências Jurídicas e Sociais voltada a solucionar o problema trazido. Para tanto, adota-se o método dedutivo para a sua construção. No que pertine a apresentação, esta centrar-se-á na compreensão e exposição dos fenômenos estudados de forma descritiva e explicativa. Ademais, tem-se que a presente pesquisa é qualitativa no que se refere à seleção das referências atinentes ao tema proposto, as quais são eminentemente bibliográficas e documentais.

\section{A LIBERDADE DE RELIGIÃO DOS MUÇULMANOS NA CONTEMPORANEIDADE E A QUESTÃO DA (IN)TOLERÂNCIA.}

A liberdade religiosa é considerada um direito humano fundamental, consagrado em diversas constituições, bem como por tratados internacionais, tratandose, portanto, de uma "liberdade pública" ou de uma prerrogativa individual em face do poder estatal (SORIANO, 2002, p. 5). Segundo Ferreira (1998, p. 102), “a Liberdade Religiosa é o direito que tem o homem de adorar a seu Deus, de acordo com a sua 
crença e o seu culto". Noutros termos, o homem é livre para manifestar-se e expor-se de acordo com os ensinamentos e doutrina da religião que escolheu cultuar.

Dito isso, entende-se que é inerente à liberdade religiosa, o direito de ter, não ter ou deixar de ter uma religião, de participar, de deixar de participar ou não participar de uma atividade cultual. Logo, mesmo que se assegure o direito de se autodeterminar, estas condições fundantes não podem enclausurar o seu aderente, na medida em que ele só se vincula por vontade própria, protegendo-se sempre a inviolabilidade da sua consciência e de suas crenças, pois, "liberdade de expressão religiosa não se confunde com liberdade de opressão religiosa" (BATISTA, 2015, p. 21).

Concebida como um direito de primeira dimensão, a liberdade religiosa impõe ao Estado, "um dever de não-fazer, de não-atuar, de abster-se, enfim, naquelas áreas reservadas ao indivíduo" (BASTOS, 2013, p. 182). Desse modo, trata-se de uma prerrogativa individual oponível ao Estado, cabendo a ele proteger esse direito em face de eventuais violações cometidas por outras pessoas, sejam elas públicas ou particulares. (SORIANO, 2002, p. 6).

Por outro lado, o Estado, em alguns casos, tem obrigações positivas de fazer ou de atuar, não sendo aceitável que a efetivação constitucional do direito à liberdade religiosa se restrinja a uma mera delimitação da atuação dos poderes públicos, impedindo a sua interferência na esfera individual e, ao mesmo tempo, permitindo que esse direito fosse constantemente cerceado por indivíduos em geral, até mesmo, por atos emanados dos três Poderes (SORIANO, 2002, p. 6-7). Ainda nesse interim, afirma Miranda (2000, p. 409) no que tange os deveres do Estado para com o indivíduo, em razão da sua liberdade religiosa:

\footnotetext{
A liberdade religiosa não consiste apenas em o Estado a ninguém impor qualquer religião ou a ninguém impedir de professar determinada crença. Consiste, ainda, por um lado, em o Estado permitir ou propiciar a quem seguir determinada religião o cumprimento dos deveres que dela decorrem (em matéria de culto, família ou de ensino, por exemplo) em termos razoáveis.
}

À vista disso, a efetividade da liberdade religiosa tem como desafio central a laicidade estatal, pois um Estado laico é garantia essencial ao exercício dos direitos humanos, como bem demonstra Piovesan (2012, p. 50): 
de sociedade aberta, pluralista e democrática. A ordem jurídica em um Estado Democrático de Direito não pode se converter na voz exclusiva da moral de qualquer religião. Os grupos religiosos têm o direito de constituir suas identidades em torno de seus princípios e valores, pois são parte de uma sociedade democrática. Mas não têm o direito de pretender hegemonizar a cultura de um Estado constitucionalmente laico.

Oportuno é o momento para distinguir as expressões laicidade estatal e separação entre Estado e Religião, de laicismo e de uma postura de menosprezo e desconsideração das religiões por parte dos Estados que, respectiva e sinteticamente significam, neutralidade e hostilidade.

\begin{abstract}
Há que distinguir entre laicidade e separação (no sentido de independência) entre Estado e Igreja (e comunidades religiosas em geral) de laicismo e de uma postura de menosprezo e desconsideração do fenômeno religioso (das religiões e das entidades religiosas) por parte do Estado, pois uma coisa é o Estado não professar nenhuma religião e não assumir fins religiosos, mantendo uma posição equidistante e neutra, outra coisa é assumir uma posição hostil em relação à religião e mesmo proibitiva da religiosidade(MIRANDA; MEDEIROS, 2009, p. 448-449).
\end{abstract}

Ressalta-se que o problema da convivência frente ao pluralismo de crenças é uma questão atemporal, com a qual a humanidade não aprendeu a lidar. As minorias étnicas, linguísticas, raciais, sem dúvida, são as que mais sofrem com a intolerância (SORIANO, 2002, p. 24). Se dada religião é tomada como "melhor" ou "preferencial", comparativamente às outras religiões que estejam presentes em dada sociedade (e sejam quais forem os argumentos usados), automaticamente o grupo de adeptos dessa religião passará a gozar de privilégios e distinção que excluirão os demais, ferindo, assim, o princípio da dignidade da pessoa humana (FISCHMANN, 2012, p. 45).

Nesse passo, verifica-se a importância dessa liberdade pública envolvendo religião e Estado, já que ela reflete em diversos âmbitos sociais - e não apenas no íntimo de quem crê (MIRANDA; MEDEIROS, 2009, p. 405). Logo, tão básico é o direito à liberdade de crença presente no foro íntimo de cada um, que qualquer ameaça, incluindo a que se volta para a própria possibilidade de sua existência, torna-se ameaça à integridade da identidade de cada um, de grupos e da própria sociedade (FISCHMANN, 2012, p. 17).

Nesse viés, se não há fronteiras para o pensamento, então, o Direito Internacional atua frente às fronteiras físicas que existem quando o indivíduo expressa sua crença publicamente sendo capaz de influenciar (positivamente ou não) o 
ambiente em que se encontra.

Entende-se que a "a liberdade religiosa deve ser compreendida, construída e exercida, também, em um ambiente de tolerância e coexistência pacífica, que devem ser garantidos pelo Estado", de modo que sem tal atuação, esse direito pode restar violado, tal como ocorre com a discriminação de muçulmanos na contemporaneidade, já que se trata de um direito básico do homem, o qual deve ser tutelado e respeitado, especialmente pelos Estados onde esses indivíduos estão inseridos (BATISTA, 2015, p. 25).

Problema esse que se acentua nas relações internacionais com o fatídico episódio do atentado de 11 de setembro de 2001, uma vez que o ataque às Torres Gêmeas nos Estados Unidos comprometeu globalmente os mecanismos de proteção aos direitos, garantias e liberdades dos indivíduos, sob o argumento dos Estados estarem limitando esses direitos com o fito de assegurar a ordem e a segurança pública. Piovesan (2012, p. 64) expõe essa problemática de preservar ou limitar os direitos humanos e evitar a propagação da intolerância, realçando o dilema enfrentado pelas relações internacionais pós-atentado:

\begin{abstract}
O desafio de combater todas as formas de intolerância se soma ao desafio, que realça o dilema de preservação dos direitos e das liberdades públicas no enfrentamento ao terror. No cenário do pós-11 de setembro, o risco é que a luta contra o terror comprometa o aparato civilizatório de direitos, liberdades e garantias, sob o clamor de segurança máxima.
\end{abstract}

Em que pese o preconceito estar presente nas relações sociais entre indivíduos que seguem culturas diferentes, mas que dividem o mesmo espaço geográfico, é possível notar que após o 11 de setembro essas relações ficaram mais estreitas com os seguidores da religião islâmica. Como exemplo, pode-se citar o início de debates internos acerca da possibilidade de proibir o uso dos véus islâmicos e demais símbolos caracterizantes da religião (COLLARES, 2011, p. 1).

De encontro ao discurso democrático em que a defesa das liberdades individuais é cada vez mais valorizada no Direito Internacional, o parlamento francês aprovou uma lei em 13 de julho de 2010, em vigor desde o início de 2011, que proíbe o uso do véu pelas mulheres muçulmanas em locais públicos na França (COLLARES, 2011, p. 1-7). Segue, em síntese, alguns aspectos da lei: 
peculiaridade da cultura islâmica e impondo sua retirada em nome de um valor universal, de tal modo que mulheres islâmicas seriam vistas como simples mulheres querem sejam católicas, protestantes, anglicanas, entre outras, sem possuir uma identificação religiosa no âmbito público. Outro aspecto a se contestar seria a aplicação uniforme de direitos justificados na questão dos valores universais. A política de reconhecimento igualitário adotada pelo Estado francês reflete o formalismo do liberalismo de direitos, que não tolera a diferença, pois propaga uma aplicação uniforme de direitos, não preservando a diversidade cultural (COLLARES, 2011, p. 7-12).

A Comissão Europeia e o Conselho da Europa pronunciam-se contra o uso de restrições à vestimenta, por atentar contra a liberdade religiosa, no entanto, há iniciativas em muitos países, como a Bélgica, Holanda, Dinamarca e Itália, no sentido de se vetar a utilização de qualquer tipo de pano ou adereço que cubra a cabeça da pessoa, sem distinção (BATISTA, 2010, p. 51).

Reforça-se que, o uso do véu pelas mulheres muçulmanas é, principalmente, um ato de obediência a Deus, ou seja, é uma manifestação religiosa das mulheres muçulmanas, que é garantida pelos principais instrumentos internacionais de proteção aos direitos humanos. Não se pode despi-las, assim, sem ocasionar imensos prejuízos pessoais e sociais (COLLARES, 2011, p. 1-7).

Em outras palavras, explana-se a importância dos elementos que representam uma religião, reforçando que o véu é símbolo máximo da religião muçulmana às mulheres que a seguem:

\begin{abstract}
Se o véu consiste em um dos elementos representativos da religião, a qual a mulher muçulmana professa e aceita, e considerando-se que o processo de reconhecimento ocorre por meio de umdiálogo tanto na esfera íntima como na esfera pública, sendo a religião uma das formas de composição da autenticidade do ser; o véu representa parte da identidade da muçulmana, tanto no seu "eu", dentro dos dogmas de sua religião, como do seu "eu" dentro da sociedade civil em que vive. Desse modo, tem-se os primeiros indícios de uma forma defalso reconhecimento implementada pela política estatal francesa, haja vista que um dos elementos da identidade da mulher muçulmana está sendo proibido na esfera pública (COLLARES, 2011, p. 10-11). [grifo nosso]
\end{abstract}

Em vista disso, surge a preocupação dos muçulmanos franceses (e de todos aqueles que são proibidos por lei de não utilizá-la) de que as "leis do véu islâmico" sejam capazes de estigmatizar os muçulmanos, o que não deixa de ser uma preocupação infundada, dado o aumento, no mundo, a aversão pelo Islã ou, simplesmente, pelos muçulmanos. Nessa esteira, tal preocupação fundamenta-se na importância da preservação cultural e da simbologia religiosa a quem mantem os dogmas religiosos fora do seu país originário e, neste caso, especificamente, os 
muçulmanos são quem clamam respeito e sua devida inclusão nos países onde estão inseridos. Acerca disso, defende-se que:

A consciência de formar uma comunidade é criada através do uso de símbolos e da repetição de ritos que dão forças aos membros individuais da nação. Favorecendo ocasiões em que eles podem sentir-se unidos, e exibindo emblemas, símbolos, que representem sua unidade. [...] Os símbolos não tem valor para aqueles que não o reconhecem. Dessa forma, proporcionam um mecanismo revelador para distinguir entre membros e "estranhos" e para elevar nas pessoas a consciência e a sensibilidade dos seus pactos comunitários (COLLARES, 2011, p. 5).

Não obstante, é por causa da sua fé que os muçulmanos têm sido considerados uma ameaça à segurança e uma afronta aos valores fundamentais europeus, como a democracia e os direitos humanos (GONÇALVES, 2013, p. 93-100).

\begin{abstract}
O consenso sobre a "ameaça islâmica" é de tal modo amplo e a hostilidade contra os muçulmanos é vista com tanta naturalidade que não é difícil aos decisores políticos europeus fazer aprovar, com mínima resistência, medidas legislativas altamente restritivas da liberdade religiosa dos muçulmanos, proibindo e até criminalizando aspectos da prática religiosa que não podem deixar de considerar-se abrangidos pela liberdade de religião e de culto, reconhecida por todos os Estados europeus nas suas ordens jurídicas internas e consagrada na Convenção Europeia dos Direitos do Homem (CEDH)(GONÇALVES, 2013, p. 95-102).
\end{abstract}

Afirmando a existência da referida "ameaça islâmica", Huntington (1997, p. 269) explana que:

O crescente antiocidentalismo muçulmano foi acompanhado paralelamente por uma preocupação crescente com a "ameaça islâmica", representada em especial pelo extremismo muçulmano. O Islã é visto como fonte de proliferação nuclear, terrorismo e, na Europa, imigrantes indesejados. Essas preocupações são compartilhadas tanto pelo povo como pelos líderes.

Diante do exposto, é apropriado ressaltar que, no artigo $5^{\circ}$ do Pacto Internacional dos Direitos Civis e Políticos encontra-se uma barreira às leis que impedem o uso do véu islâmico em locais públicos, como salienta Comparato (2010. p. 305):

\footnotetext{
$\mathrm{Na}$ alínea primeira, reconhece-se que o limite intrínseco da liberdade consiste no impedimento de agir contra os direitos humanos, de forma a destruí-los praticamente, ou a impor-Ihes restrições mais amplas que as já previstas no direito vigente. Na segunda alínea, enuncia-se o princípio da prevalência da norma mais favorável à pessoa humana, em caso de não concorrência de normas sobre o mesmo objeto. Com isto, estabelece-se também que, em matéria de direitos humanos, não se admitem regressões, por meio de revogação normativa, ainda que efetuada por diplomas jurídicos de hierarquia de hierarquia superior àquele em que foram tais direitos anteriormente
} 
declarados.

Por conseguinte, é inegável a sobreposição de uma cultura à outra, isto é, uma defesa exacerbada de uma cultura predominante sobre uma cultura minoritária. Noutros termos, independente do argumento dos governos que limitam o uso da burca de que estas leis visam preservar a dignidade humana e a igualdade entre os sexos, na realidade tal está fomentando a política da intolerância, sendo, também, neste caso tanto cultural quanto religiosa em relação aos muçulmanos (COLLARES, 2011, p. 12). Portanto, o Estado que deveria assegurar tal direito, torna-se o responsável pela propagação da discriminação e de violações de direitos humanos fundamentais de uma minoria religiosa em seu território.

Além disso, especificamente em relação às minorias, na Convenção sobre a Eliminação de Todas as Formas de Discriminação Racial de 1965, nos artigos da 26 e 27, aqui considerados em conjunto, define-se discriminação como sendo "toda distinção, exclusão, restrição ou preferência"; porém, o conceito de minoria foi definido em um relatório, aprovado em 1977, no qual a Subcomissão contra as Medidas Discriminatórias e de Proteção das Minorias, subordinada à então existente comissão de Direitos Humanos (Desde 2006 - Conselho de Direitos Humanos) explicou-se que, na noção de minoria, existem quatro critérios de natureza objetiva e/ou um de natureza subjetiva:

\footnotetext{
Quatro são os critérios conceituais de natureza objetiva, para o reconhecimento de uma minoria populacional. O primeiro deles é a existência, no seio da população de um Estado, de grupos que se distinguem por características étnicas, religiosas ou linguísticas estáveis, nitidamente diferentes das que prevalecem no restante da população. O segundo critério, decorrente do próprio sentido literal do termo, é de ordem numérica: tais grupos não devem constituir a maioria da população. Em terceiro lugar, porém, a noção de minoria discriminada pressupõe o fato político de que tais grupos não se encontram em situação de poder da sociedade: a proteção exigida pela norma do artigo 27 não diz respeito, como é óbvio, às minorias oligárquicas. Em quarto e último lugar, a discriminação violadora desse direito humano supõe que discriminadores e discriminados pertencem ao mesmo Estado. Aduz-se, ainda, como critério subjetivo para o reconhecimento de uma minoria, que o grupo em questão manifesta, inequivocamente, o desejo de preservar sua identidade cultural (COMPARATO, 2010. p. 335-337).
}

E, ainda, prezando pela garantia dos direitos das minorias religiosas, em 18 de dezembro de 1992, a Assembleia Geral da ONU aprovou uma "Declaração sobre os Direitos de Pessoas Pertencentes a Minorias Nacionais, ou Étnicas, Religiosas ou Linguísticas" que, em seu artigo $2^{\circ}$, afirma: 
1. As pessoas pertencentes a minorias nacionais ou étnicas, religiosas e linguísticas (doravante denominadas "pessoas pertencentes a minorias") têm o direito de fruir a sua própria cultura, de professar e praticar a sua própria religião, e de utilizar a sua própria língua, em privado e em público, livremente e sem interferência ou qualquer forma de discriminação.

2. As pessoas pertencentes a minorias têm o direito de participar efetivamente na vida cultural, religiosa, social, económica e pública.

3. As pessoas pertencentes a minorias têm o direito de participar efetivamente nas decisões adoptadas a nível nacional e, sendo caso disso, a nível regional, respeitantes às minorias a que pertencem ou às regiões em que vivem, de forma que não seja incompatível com a legislação nacional.

4. As pessoas pertencentes a minorias têm o direito de criar e de manter as suas próprias associações.

5. As pessoas pertencentes a minorias têm o direito de estabelecer e de manter, sem qualquer discriminação, contatos livres e pacíficos com os restantes membros do seu grupo e com pessoas pertencentes a outras minorias, bem como contatos transfronteiriços com cidadãos de outros Estados com os quais tenham vínculos nacionais ou étnicos, religiosos ou linguísticos.

A partir desses documentos comprova-se, então, que o manto global de proteção aos direitos humanos, mais especificamente ao direito à liberdade de religião, é de uma larga dimensão. Não sendo racional e justo que uma lei interna, sem fundado motivo, seja capaz de privar seus cidadãos (minoritários ou não) de praticar livremente sua religião. Afinal, "o 11 de setembro e seus desdobramentos não podem impedir o diálogo entre culturas diferentes em pleno século XXI. Nessa medida, uma lei dessa natureza exacerba a intolerância e a convivência entre as partes" (COLLARES, 2011, p. 13).

Faz-se necessário, assim sendo, de um diálogo intercultural como reflexo do atentado, o qual inclui uma maior atenção a esses grupos minoritários residentes em países ocidentais, à luz do direito internacional. Corrobora com esse posicionamento Montiel (2003, p. 16), para quem:

Diante dos lamentáveis acontecimentos sucedidos em setembro de 2001, que tantas indignações e interrogações levantaram, de imediato, foi nas culturas onde se buscavam as respostas, as chaves para se entender o ocorrido. Os estudos culturais e a geopolítica das culturas subitamente mostram sua pertinência, colocando em evidência o empenho da Unesco em promover o diálogo intercultural, o fomento do pluralismo e da tolerância. Dever-se-ia indagar em relação a tudo isso se aqui não se trata, como se diz com insistência, de um choque de civilizações, ou melhor, como nos parece, de um conflito de indiferenças, de culturas que jamais dialogam ou, ao menos, não o suficiente para se entenderem, e que agora, visivelmente, graças às tecnologias de comunicação, co-habitam num mesmo tempo e espaço.

\section{A Organização das Nações Unidas para Educação, Ciência e Cultura} (UNESCO), também adota essa visão, a qual restou explícita na "Declaração Universal da Unesco sobre a Diversidade Cultural de 2002", reafirmando a certeza de que o 
diálogo intercultural é o meio mais adequado para a promoção da paz, da tolerância e do respeito ao outro (POTTUMATI, 2014), como vê-se pelo teor do documento "afirmando que o respeito à diversidade das culturas, à tolerância, ao diálogo e à cooperação, em um clima de confiança e de entendimento mútuos, estão entre as melhores garantias da paz e da segurança internacionais" (UNESCO, 2002).

Apesar disso, lamentavelmente, cumpre destacar que a intolerância, como herança cultural, ainda é muito presente no mundo, uma vez que "a defesa da tolerância se faz depois de séculos de intolerância e do uso indiscriminado da força e da violência por aqueles que deveriam professar e disseminar exatamente a paz e o amor universal" (GONÇALVES, 2013, p. 97-110). A intolerância, interpretada por Wiesel (2000 apud GONÇALVES, 2013, p. 97), quando instalada na sociedade, fomenta o ódio entre os indivíduos, de modo que um Estado laico seria o início para a reversão à uma tolerância religiosa. Nas suas palavras:

\begin{abstract}
A intolerância está situada no começo do ódio. Ela assume aparências tão sutis que fica difícil discerni-la e combate-la. E, no entanto, "se não a detivermos, será tarde demais". Uma vez instalada, gera inevitavelmente o desprezo, o ódio pelo outro; e o ódio, por sua vez, só gera o ódio. A noção moderna de tolerância está intrinsecamente ligada à posição dos Estados acerca de uma neutralidade religiosa em seu cerne. Em outras palavras, quanto mais laico for o Estado e quanto mais professar a liberdade religiosa, maior será a tolerância religiosa.
\end{abstract}

Por outro lado, fomentando-se uma sociedade tolerante que visa a paz, a consequência seria o desenvolvimento de uma "sociedade fraterna, justa e pluralista", pois a verdadeira tolerância liberta o indivíduo da violência e da opressão, além de não se apresentar como incapacidade à autodeterminação (SORIANO, 2002, p. 23). Isto é, "em seu sentido mais profundo, a tolerância está intensamente enraizada no valor supremo do respeito aos direitos inalienáveis da pessoa humana, quando há o seu reconhecimento teórico e prático" (BATISTA, 2010, p. 100). No mesmo sentido, tece Bobbio (1992, p. 203), que:

\footnotetext{
Quando se fala em tolerância nesse seu significado histórico predominante, o que se tem em mente é o problema de convivência de crenças (primeiro religiosas, depois também políticas) diversas. Hoje, o conceito de tolerância é generalizado para o problema da convivência das minorias étnicas, linguísticas, raciais, para os que são chamados geralmente de diferentes.
}

A importância da tolerância e respeito entre pessoas que possuem opiniões culturais divergentes é fundamental, principalmente, no tocante à religião, pois tolerar o 
outro não significa que suas diferenças e contradições não existem mais ou que se abdicou da sua crença, como forma de aceitação à crença e cultura de outrem. Observa-se que "uma atitude tolerante pode perfeitamente coexistir com uma solida fé e com a tentativa de converter os outros. Porém, a tolerância não é compatível com atitudes como zombar das opiniões alheias ou se utilizar da força e de ameaças, porquanto, não se limita ao direito de fazer propaganda, mas exige que seja feita com respeito pela opinião dos outros" (GAARDER, 2000, p. 14-15).

Ainda nesse contexto, esclarece-se que, "tolerância não é convivência com o intolerável". Quer isso dizer que o sentido de tolerância deve encaixar-se, de forma equilibrada, à identidade de cada indivíduo e a diversidade encontrada na sociedade (BATISTA, 2010, p. 101). Pressupõem-se, que "a comunicação intercultural é o estabelecimento de pontos de contato entre as culturas que viabiliza o diálogo e, com ele, a possibilidade de compreensão e do respeito mútuo" (CARDOSO, 2003, p. 12).

Com esse intuito, o "Encontro sobre a Tolerância na América Latina e no Caribe de 1994 no Rio de Janeiro", apresentou um novo verbete para o termo tolerância sob uma hodierna perspectiva, neutra e despida de preconceitos Ocidentais, respeitando as diversidades culturais e agregando os principais valores de uma sociedade global (CARDOSO, 2003, p. 12).

Tolerância, s. f. Atitude de reconhecimento, na teoria e na prática, do outro como outro e de respeito mútuo às diferenças; - capacidade de diálogo, de compreensão e de respeito mútuo entre posições tolerantes com ideias e valores diferentes; - respeito aos direitos universais inalienáveis da pessoa humana; - reconhecimento da diversidade cultural, contrapondo-se à hegemonia de uma cultura que domina e marginaliza as outras; - resistência a tudo aquilo que provoca opressões e desigualdades sociais; - ação solidária na superação das desigualdades sociais; - valorização da diversidade cultural a partir da consciência clara do valor da própria identidade e de seus limites; capacidade de cooperação para alcançar objetivos comuns; - atitude de solidariedade entre indivíduos, grupos, povos, nações e, também, dos seres humanos para com a natureza em geral.

Tem-se, portanto, que a "tolerância é o reconhecimento da diversidade cultural a partir da valorização da identidade de sua própria cultura”, pois a identidade cultural não é estática, tampouco se encontra acabada; pelo contrário, apresenta-se em constante transformação "com a dissolução de aspectos culturais do passado e com a assimilação de novas culturas no contato com outros povos" no presente. Por esse motivo, "a consciência de sua identidade passa necessariamente pelo" (re)conhecimento "das relações históricas com as outras culturas" (CARDOSO, 2003, 
p. 14).

Isto é, "a tolerância é necessária para a sobrevivência de cada cultura na sua singularidade, uma vez que não existe mais uma utopia comum que nos identifica como comunidade humana". Com isso, conclui-se que a interpretação das relações culturais apresenta mudanças no seu foco, expandindo-se e considerando a possibilidade da existência de uma multiplicidade de culturas dialogando em um mesmo espaço, ou seja, a existência de um multiculturalismo (CARDOSO, 2003, p. 13).

\section{A DEFESA DA LIBERDADE RELIGIOSA PELA ADOÇÃO DO VIÉS MULTICULTURAL.}

A adesão formal dos tratados internacionais de direitos humanos por parte dos Estados Orientais não se mostra tão significativa quanto o número de adesões de Estados Ocidentais. Ademais, há certa dificuldade de aceitar-se em localidades Orientais sugestões de políticas públicas que reivindiquem certas ações em prol da proteção de direitos humanos exatamente por imprimirem conceitos não adequados a tal região, haja vista o seu "viés cultural ocidental predominante" (PEIXOTO, 2007, p. 12).

Em decorrência disso, é natural questionar-se o sentido que os direitos humanos possuem na sociedade atual, posto que a sua interpretação pode realmente variar de localidade para localidade. Além disso, somado às discussões acerca de intolerância religiosa realizadas supra, é evidente a dificuldade enfrentada por essa sociedade, marcada pelas transformações do novo milênio, em se relacionar com a diversidade cultural, indicando a impossibilidade de acatar-se o universalismo dos direitos humanos enquanto teoria passível de garantir uma maior efetividade a esses direitos.

Sem dúvidas, esse é um dos maiores dilemas em relação aos direitos humanos na atualidade. A eficácia dos direitos humanos depende das suas teorias de base, afinal, se considerados universais, eles deveriam ser aplicados à todos, indiferentemente de onde estiverem os indivíduos, exatamente pela sua natureza intrínseca e indissociável do homem, em que pese ser essa visão bastante excludente, exatamente por não considerar as diferenças existentes entre os próprios homens quanto ao seu gênero, cor, raça, origem, crença, entre outros, os quais termina por 
padronizar a sociedade - justamente a resposta contrária para a o combate da intolerância (incluindo a religiosa).

Outrossim, a interpretação relativista cultural radical tampouco mostra-se efetiva, haja vista que ela permitiria a adoção de visões extraordinárias acerca dos direitos humanos, os quais tenderiam a excluir a própria humanidade existente no indivíduo, posto que fechar-se-ia na sua posição, sem quaisquer inputs oriundos de outras culturas, o que igualmente levaria à intolerância, tal como na visão universalista. Logo, é possível dizer que ambas essas teses de fundamentação de direitos humanos demonstraram falhas e acabam por não atingir o objetivo central demandado.

Com o intuito de resolver o embate entre as teorias de fundamentação, propõese que se deixe de fundamentá-las separadamente, pois enquanto houver a dicotomia entre as teorias universalista e relativista, o problema de interpretação e aplicação dos direitos humanos, persistirá (FRANÇA, 2016). Então, pensa-se ser adequado defenderse a liberdade religiosa pela adoção do viés multicultural, já que nele vislumbra-se um manto maior de proteção aos direitos humanos considerando as peculiaridades de cada localidade, sem a exclusão de eventuais comunicações, mas também sem o condão de padronizar e afastar as diferenças.

O multiculturalismo nasce da ideia do diálogo intercultural, o qual, tal como esclarece Eberhard (2004, p. 161), “não deve [...] ser interpretado como uma postura completamente relativista, ou como a negativa de qualquer universalidade ou de qualquer relevância dos direitos humanos". "Essa teoria não pretende impor uma colonização de direitos ocidentais, muito menos ambiciona a justificação de cometimento de crimes por parte de um Estado opressor" (SQUEFF; TEIXEIRA, 2015, p. 138-167).

Da mesma forma, Santos (2003, p. 253), propõe a identificação de cinco premissas que visam "transformar a conceptualização e a prática dos direitos humanos, de um localismo globalizado, num projeto cosmopolita" (SANTOS, 2003, p. 247-248). Isto é, busca-se permitir que os direitos humanos transformem-se de uma visão limitada a uma visão múltipla, em relação ao seu conceito quanto a sua aplicação. Ato contínuo, no que tange as premissas citadas pelo referido autor, entende-se que:

A primeira premissa é a superação do debate sobre universalismo e relativismo cultural. Trata-se de um debate intrinsicamente falso, cujos conceitos polares são igualmente prejudiciais para uma concepção emancipatória de direitos 


\begin{abstract}
humanos. A segunda premissa da transformação cosmopolita dos direitos humanos é que todas as culturas possuem concepções de dignidade humana, mas nem todas elas a concebem em termos de direitos humanos. Torna-se, por isso, importante identificar preocupações isomórficas entre diferentes culturas. A terceira premissa é que todas as culturas são incompletas e problemáticas nas suas concepções de dignidade humana. A incompletude provem da própria existência de uma pluralidade de culturas, pois se cada cultura fosse tão completa como se julga, existiria apenas uma só cultura. (...) aumentar a consciência de incompletude cultural é uma das tarefas prévias à construção de uma concepção multicultural de direitos humano. A quarta premissa é que todas as culturas têm versões diferentes de dignidade humana, algumas mais amplas do que outras, algumas com um círculo de reciprocidade mais largo do que outras, algumas mais abertas a outras culturas do que outras. A quinta premissa é que todas as culturas tendem a distribuir as pessoas e os grupos sociais entre dois princípios competitivos de pertença hierárquica. O princípio da igualdade e o princípio da diferença. Embora na prática os dois princípios se sobreponham frequentemente, uma política emancipatória de direitos humanos deve saber distinguir entre a luta pela igualdade e a luta pelo reconhecimento igualitário das diferenças a fim de poder travar ambas as lutas eficazmente (SANTOS, 2003, p. 253-255).
\end{abstract}

Em suma, as premissas abordam a possibilidade de superar o debate entre as teorias de interpretação dos direitos humanos; de identificar, em meio as diferenças culturais, consonância; de conscientizar as culturas de suas mútuas incompletudes; de identificar o significado de dignidade humana para cada cultura; e por fim, compreender a hierarquia de aplicação dos princípios da igualdade e da diferença(SANTOS, 2003, p. 253-255).

Identificadas tais premissas ao diálogo intercultural, o autor propõe que se identifique o método/instrumento de efetivação da transformação e redefinição dos direitos humanos, a chamada hermenêutica diatópica. Embasa-se, a hermenêutica diatópica, em não interpretar uma cultura a partir do topos de outra. "Os diálogos interculturais são, então, essenciais para confirmar as incompletudes das culturas existentes e para caminhar em busca de concepções multiculturais de direitos humanos" (PEIXOTO, 2007, p. 12).

Assim explica Santos (2003, p. 442):

\begin{abstract}
A incompletude provém da própria existência de uma pluralidade de culturas, pois se cada cultura fosse tão completa quanto se julga, existiria apenas uma só cultura. A idéia de completude está na origem de um excesso de sentido de que parecem sofrer todas as culturas e é por isso que a incompletude é mais facilmente perceptível do exterior, a partir da perspectiva de outra cultura. Aumentar a consciência de incompletude cultural é uma das tarefas prévias para a construção de uma concepção multicultural de direitos humanos.
\end{abstract}

A hermenêutica diatópica promove um diálogo intercultural/multicultural sobre os direitos humanos e outros princípios da dignidade humana afim de transformar a 
prática dos direitos humanos em um projeto cosmopolita (TAVARES, 2010). Refletindo sobre o assunto, surge a pergunta: Não seria utopia acreditar nesse diálogo intercultural? Santos (2003, p. 458) responde: "Certamente é, tão utópico quanto o respeito universal pela dignidade humana. E nem por isso este último deixa de ser uma exigência ética séria".

A integração dos dois princípios da hermenêutica diatópica, os quais se tornam complementares, e não excludentes, formam um imperativo transcultural, explica o autor Boaventura de Sousa Santos, "a hermenêutica diatópica pressupõe a aceitação do seguinte imperativo transcultural: temos o direito a ser iguais quando a diferença nos inferioriza; temos o direito a ser diferentes quando a igualdade nos descaracteriza" (SANTOS, 2003, p. 458).

Vimos os benefícios que a hermenêutica diatópica oferece à sociedade global e a importância de haver um diálogo intercultural para melhor alcançar os objetivos dos direitos humanos, contudo, "uma concepção idealista de diálogo intercultural poderá esquecer facilmente que tal diálogo só é possível através da simultaneidade temporária de duas ou mais contemporaneidades diferentes" (SANTOS, 2004, p. 265).

Quer isto dizer que, quando duas ou mais culturas forem dialogar, levar-se-ão com elas suas raízes históricas, e não só suas atuais características sociais e culturais. Tal iniciativa, pode causar, ou até mesmo aumentar, uma possível tensão entre elas, principalmente, "quando as diferentes culturas envolvidas no diálogo partilham um longo passado de trocas sistematicamente desiguais" (SANTOS, 2004, p. 266).

Portanto, ao propor um diálogo intercultural é necessário que os envolvidos sigam as devidas orientações e que os imperativos transculturais, propostos pelo autor, sejam aceitos "por todos os grupos sociais e culturais interessados no diálogo", para que assim, não ocorra nem um "fechamento cultural" nem uma "conquista cultural" por parte de culturas tidas como dominantes na sociedade global (SANTOS, 2004, p. 266). Assim, trilha-se o caminho para uma concepção multicultural dos direitos humanos.

A importância do reconhecimento nas relações sociais, também é analisa pelo autor Charles Taylor, ao afirmar que "muito da vida social e política moderna gira em torno das questões de reconhecimento". Nessa mesma linha, o autor, também, demonstra sua explicação abordando elementos básicos como a identidade e autenticidade do indivíduo: 
questão de reconhecer os indivíduos e o que chamamos de suas identidades. Também temos a noção, que vem da ética da autenticidade, que, se outras coisas são iguais, as pessoas têm o direito de serem reconhecidas publicamente por aquilo que elas realmente já são. É porque alguém já é autenticamente judeu ou homossexual que lhe negamos algo ao exigir-lhe que esconda esse facto, que possa ser algo que não é(TAYLOR, 2014, p. 166).

Além disso, Eberhard (2004, p. 165) salienta que, "sem o reconhecimento, não há compartilhamento, e sem o compartilhamento, não se pode alcançar o consenso nem construir um futuro comum". Por isso, não basta o simples reconhecimento, existe a necessidade de estabelecer diálogos interculturais no direito internacional (SQUEFF; TEIXEIRA, 2015, p. 160). E, esses diálogos devem sempre observar, de preferência, o fundamento da tolerância.

Abordou-se no primeiro ponto deste texto a questão da (in)tolerância e seus efeitos na sociedade, de modo que, neste ponto, abordar-se-á a tolerância para demonstrar a sua essencialidade à defesa dos fundamentos multiculturalistas de proteção aos direitos humanos, pois consideram as transformações históricas, culturais e religiosas dos povos à "real efetividade dos ditames internacionais nos mais diversos foros"(SQUEFF; TEIXEIRA, 2015, p. 160-161).

Bobbio (2004, p. 87-88), para demonstrar o papel fundamental da tolerância nas sociedades, focando-se na tolerância religiosa, conta rapidamente um trecho do livro de Thomas Morus, tecendo a seguinte consideração:

\footnotetext{
Na ilha da Utopia, pratica-se a tolerância religiosa; e Utopo explica as suas razões do seguinte modo: "Seria temerário e tolo (Insolens et ineptum) pretender, através de violências e ameaças, que aquilo que tu crês verdadeiro apareça como tal para todos. Além do mais, sobretudo se só uma religião fosse verdadeira e todas as outras falsas, (Utopo) prevê que, no futuro, contanto que se proceda de modo racional e moderado, a verdade virá finalmente à luz, impondo-se por seus próprios méritos. Se, ao contrário, as contendas se dessem entre armas e brigas, dado que precisamente os piores são os mais obstinados, a melhor e mais santa das religiões estaria destinada a ser esmagada na luta, em meio às mais vãs superstições, como trigo em meio ao joio."
}

Cumpre esclarecer que, nesse trabalho optou-se por utilizar-se como exemplo a relação dos muçulmanos com os Europeus, mais especificamente, com a França, pois se levou em consideração os atuais conflitos e hostilidade do país com o povo de origem árabe, seguidores do Islamismo. E, tendo em vista isso, destaca-se que historicamente, "nos primeiros anos da década de 90, dois terços dos migrantes na Europa eram muçulmanos e a preocupação europeia com a imigração era sobretudo com a imigração muçulmana" (HUNTINGTON, 1997, p. 250).

Revista de Direitos Fundamentais \& Democracia, Curitiba, v. 26, n. 1, p. 59-86, jan./abr. 2021. 
Huntigton (1997) destacou que a maior preocupação e desafio dos Europeus era demográfica e cultural, uma vez que, "as comunidades muçulmanas, não se integraram nas respectivas culturas anfitriãs e, para a preocupação dos europeus, dão poucos sinais de virem a se integrar.”. (HUNTINGTON, 1997, p. 250).

Complementa o autor, observando que "os franceses são mais culturistas do que racistas em qualquer sentido estrito", pois aceitam em "sua legislatura africanos negros que falam francês perfeito, mas não aceitam meninas muçulmanas que usam lenços de cabeça nas suas escolas" (HUNTINGTON, 1997, p. 250). Para frisar a hostilidade seletiva dos europeus, citou um comentário de um jornalista norteamericano:

\begin{abstract}
A hostilidade europeia é curiosamente seletiva. Poucas pessoas na França se preocupam com uma invasão vinda do Leste - os poloneses são, afinal de contas, europeus e católicos. E, na sua maioria, os imigrantes africanos nãoárabes não são temidos nem menosprezados. A hostilidade se dirige sobretudo aos muçulmanos. A palavra immigré é praticamente sinônimo de Islamismo, atualmente a segunda maior religião na França, e reflete um racismo cultural e étnico profundamente enraizado na história francesa (HUNTINGTON, 1997, p. 250).
\end{abstract}

Com isso, percebe-se que o preconceito gerador da intolerância religiosa e cultural para com os árabes muçulmanos não é novidade, porém mostra-se atual, além de modificar-se juntamente com a sociedade ao mesmo passo em que é atingida pela globalização.

Para melhor compreender essa questão, note-se as informações sobre a população francesa, mais especificamente os muçulmanos e os imigrantes na França, no período de 1990 a 2010. Observa-se que "hoje, a Europa abriga 44 milhões de muçulmanos - o que contabiliza $6 \%$ de sua população e $2 \%$ do total de islâmicos no mundo. Nos próximos 20 anos, eles representarão $8 \%$ dos europeus, e o número deve continuar subindo, assim como a taxa de imigração geral” (REZENDE, 2011).

Com relação aos discursos extremistas e autoritários do atual presidente dos Estados Unidos, Donald Trump, e quanto ao cenário que ora apresentou-se, cabe expor a escrita de um dos maiores teóricos da tolerância, como referiu Bobbio ao citar John Locke:

\footnotetext{
Seria de desejar que um dia se permitisse a verdade defender-se por si só. Muito pouca ajuda the conferiu o poder dos grandes, que nem sempre a conhecem e nem sempre the são favoráveis (...) A verdade não precisa da violência para ser ouvida pelo espirito dos homens; e não se pode ensiná-la
} 
pela boca da lei. São os erros que reinam graças à ajuda externa, tomada emprestada de outros meios. Mas a verdade, se não é captada pelo intelecto com sua luz, não poderá triunfar com a força externa (BOBBIO, 2004, p. 8788).

Para Zarka (2013, p. 168), o plano dos direitos culturais garantiu um ponto essencial no plano da tolerância de religiões quando abordou o seguinte:

O que se trata de garantir não são os conteúdos culturais determinados, mas a possibilidade para os indivíduos de a eles aderirem livremente, isto é, de desenvolverem formas culturais, valores e modos de existência artística, religiosa ou outra. Essa imposição não implica qualquer pressuposição sobre a igualdade de valor dos conteúdos culturais. Uma tal equivalência é, de fato, totalmente insustentável.

Ou seja, o indivíduo pode optar por "perpetuar a religião e a cultura de seus ancestrais" ou separar-se delas, como também pode optar por (re)modela-las à sua vontade e necessidade. Isto é, com a combinação da teoria relativista com a tolerância "possibilita fazer passar a cultura da condição de produto do determinismo genealógico, social e histórico a um produto da liberdade" (ZARKA, 2013, p. 169). Com relação a isso, expõe o autor que "as formas culturais, religiosas, artísticas, entre outras, merecem se manter apenas na medida em que são desejadas pelos indivíduos que com ela se envolvem livremente. Pode, inclusive, ocorrer de uma língua morta ou cultura que se acredita perdida venha a renascer" (ZARKA, 2013, p. 169).

Nesse sentido, para Donnelly (2013, p. 110), a cultura é um processo histórico e institucional em curso. O autor defende que a cultura não é um dado, mas sim um conjunto de maneiras de pensar, acreditar e agir que estão constantemente no estado de ser produzido. Nessa mesma linha, o referido autor, explica que a existência de um determinado costume não significa que tal seja adaptável, ótimo ou consentido pela maioria de seus adeptos. Especialmente em um ambiente em rápida mutação, as práticas culturais sobrevivem rotineiramente à sua utilidade e novas práticas e valores surgem tanto através do diálogo interno no grupo cultural como através das influências transculturais (DONNELLY, 2013, p. 110).

Reporta-se, que o fundamento do multiculturalismo já se encontra positivado internacionalmente, ou seja, apresenta-se na Declaração de Viena de 1993 (ONU, 1993), a qual foi ratificada por 171 Estados, na qual acolheu, além da concepção universalista também a concepção relativista dos direitos humanos (SQUEFF; TEIXEIRA, 2015, p. 160-162). Ainda, segundo Alves (2005, p. 41) há quem defendaque a própria Declaração Universal de Direitos Humanos também "já havia Revista de Direitos Fundamentais \& Democracia, Curitiba, v. 26, n. 1, p. 59-86, jan./abr. 2021. 
procurado reforçar essa visão multicultural dentro de um quadro universal de direitos humanos", alegando que ela havia sido feita para (SQUEFF; TEIXEIRA, 2015, p. 161):

[...] fortalecer um mínimo denominador comum para um universo cultural variado, um parâmetro bem preciso para o comportamento de todos, um critério de progresso para as contingências desiguais de um mundo reconhecidamente injusto, um instrumento para a consecução dos demais objetivos societários sem que estes desconsiderem a dimensão humana.

Isto é, nessa perspectiva, torna-se plausível dizer que mesmo que a Declaração Universal dos Direitos Humanos tenha concebido universalmente os direitos humanos, "ela reconheceu como relevantes as particularidades nacionais e regionais refletidas como aspectos culturais" no âmbito internacional de aplicação desses direitos (SQUEFF; TEIXEIRA, 2015, p. 162-163).

Tem-se que a concepção do multiculturalismo ao pregar "o direito a ser diferente dentro de uma cultura" (SQUEFF; TEIXEIRA, 2015, p. 164), contrapõem as "imposições ocidentais e sua pretensão de generalização da concepção de universalidade dos direitos humanos" (SILVA; PEREIRA, 2013). Então, a partir de uma visão multicultural, vê-se que os muçulmanos teriam seus direitos amplamente assegurados na sociedade, uma vez que seus direitos são, predominantemente, religiosos.

Para uma compreensão acerca da globalização atual e dos fenômenos oriundos dela, além de como isso impacta no direito e no estado, fica cada vez mais difícil existir uma cultura límpida e/ou um país "puro", sem influências externas (SQUEFF, 2016, p. 19-21). Por isso, promover o diálogo intercultural, a tolerância e o respeitono direito internacional mostra-se deveras importante e encaminha-se à encontrar as soluções aos conflitos emergentes no viés do multiculturalismo (PEIXOTO, 2007, p. 12). É assim que entende Montiel (2003, p. 19-20):

\footnotetext{
Os produtos de revolução digital, com seu potencial para transmitir informações desde uma multiplicidade de centros de tempo real, fazem com que qualquer indivíduo que tenha à mão o controle remoto de um televisor ou o mouse de um computador possa transitar por um mundo de costumes, valores, mentalidades, crenças, gostos, comidas, canções, narrações ou modas das regiões mais distantes do mundo. Em virtude dessa exposição constante a novos símbolos, se estabelecem novos vínculos identificatórios, os perfis culturais mudam, mudando seus referentes tradicionais, costumes e visões originárias, para ir se organizando em função de códigos simbólicos que provêm de repertórios culturais muito diversos, que têm sua origem nos diferentes formatos eletrônicos. Desse modo, as identidades tendem a diluir-se e surgem novas formas de identificação, poliglotas, multiétnicas, migrantes,
} 
com elementos de diversas culturas.

Por consequência das influências externas, as "raízes nacionais" se modificam, podendo perder ou ganhar novas características. Assim, as pessoas ganham a possibilidade de se identificar, tanto com o que já conhecem como com o que acabam de conhecer em decorrência da mundialização. É o que exprime Vieira (2000, p. 100):

\begin{abstract}
Uma cultura mundial penetra os setores heterogêneos dos países, separandoos de suas raízes nacionais. A mundialização da cultura significa ao mesmo tempo diferenciação, descentramento, e padronização e segmentação (Ortiz, 1994), tanto no plano global como no local, que, como vimos, se fundem no conceito de 'glocal'. (...) A cultura mundializada se internaliza dentro de nós. $\mathrm{O}$ espaço local 'desencaixado' aproxima o que é distante e afasta o que é próximo, isto é, o local é influenciado pelo global, ao mesmo tempo que o influencia.
\end{abstract}

Nessa mesma linha, Guimarães (2009), aborda a importância do multiculturalismo para alcançar valores comuns internacionalmente e para possibilitar o diálogo entre as culturas, assim, fortalecendo a diversidade, mas sem que isso acabe por descaracterizar as sociedades. Em suas palavras:

[...] depende não só da construção de uma comunidade jurídica internacional, mas principalmente da consecução de uma verdadeira comunidade de valores no plano mundial, capaz de possibilitar o diálogo intercultural, isto é, o diálogo entre o local, o regional e o universal, sem ferir as peculiaridades que caracterizam cada sociedade e que são tão necessárias à identificação de cada povo no âmbito do processo de globalização (GUIMARÃES, 2009, p. 76).

Christoph Eberhard demonstra a necessidade de ampliarmos a nossa visão de mundo e, para isso, adotarmos o pluralismo cultural. Isso porque, o multiculturalismo não se fundamenta por extremos, portanto, não exclui as teorias relativistas e universalistas por completo, mas pretende aperfeiçoá-las e desenvolver-se para alcançar o diálogo intercultural sobre os direitos humanos e para ser visto como algo "construtivo ao invés de destrutivo" (EBERHARD, 2004, p. 160-161). Afinal, a visão multicultural não pretende refutar a universalidade dos direitos humanos, pelo contrário, pretende "enriquecê-la por meio de perspectivas culturais diferentes, com vistas a avançar progressivamente rumo a uma práxis intercultural dos direitos humanos e abrir novos horizontes para uma "boa vida" para todas as pessoas" (EBERHARD, 2004, p. 161).

Analisando, por fim, vê-se que não é impossível adotarmos uma "terceira via" (multicultural) de fundamentação dos direitos humanos no plano internacional, pois "é Revista de Direitos Fundamentais \& Democracia, Curitiba, v. 26, n. 1, p. 59-86, jan./abr. 2021. 
possível tentar uma fundamentação dos direitos humanos que vá além da mera opção entre universalismo e relativismo cultural" (SCALCO, 2009, p. 78). Adotando o multiculturalismo, então, englobamos a proteção do que é essencial ao indivíduo, bem como a sua essencialidade na vida e no mundo.

Ao cabo, retoma-se o questionamento de Boaventura de Sousa Santos, de que "não seria utopia acreditar nesse diálogo intercultural?" (SANTOS, 2003, p. 458). Com base no que foi visto no decorrer desse escrito, defende-se que, tratar como utopia algo que, teoricamente, é intrínseco ao ser humano, não parece adequado, uma vez que essa ideia desconstrói os pilares mais básicos dos direitos e garantias dos seres humanos, estando eles inseridos ou não em uma comunidade cultural. Pode-se entender que falta um longo percurso para chegar na concepção ideal de direitos humanos, mas internalizar isso como utópico, faz com que a esperança de um mundo melhor não passe de um sonho, de imaginação de quem realmente precisa ser respeitado no mundo, nós, os seres humanos.

\section{CONSIDERAÇÕES FINAIS}

O presente texto enfrentou a questão do direito humano fundamental à liberdade religiosa no âmbito do direito internacional público contemporâneo, tendo como ponto de partida a elaboração, ao final da Segunda Guerra Mundial, de um sistema normativo internacional de proteção dos direitos humanos, o qual situa a pessoa no centro das relações internacionais, voltando esta para a sua proteção, queira o Estado ou não. Outrossim, mesmo diante da criação de um sistema normativo internacional que pugne pela proteção plena do indivíduo, há situações que persistem em questionar a forma em que os direitos humanos são sopesados pelos Estados.

Isso porque, mesmo considerando a existência de direitos humanos, estes direitos não seriam interpretados por todos ou aplicado para todos os indivíduos da mesma forma, de modo que para alguns Estados seria natural a supressão de certos direitos quando outros estivessem em cheque - independentemente se essa conduta fira ou não o âmago do ser humano, afinal, estar-se-ia protegendo um interesse maior, superior, que é justamente a coletividade. Por outro lado, esse debate resta ainda mais perigoso se considerado o direito a liberdade de religião, haja vista a manifestação religiosa ser uma escolha personalíssima, a qual o Estado não poderia intervir, sob 
pena de não só atingir a dignidade de um indivíduo, mas também de causar uma instabilidade ainda maior no plano doméstico e internacional, sobretudo, pela potencial intolerância carregada por sua (re)ação.

Logo, um fato histórico recente na história foi abordado para melhorar entender a problemática proposta por esse escrito, a saber, o da liberdade de religião dos muçulmanos e a questão da (in)tolerância, a partir dos atentados terroristas ocorridos nos Estados Unidos em setembro de 2001. Afinal, a partir dessa data os Estados começaram a limitar garantias, direitos e liberdades públicas de seguidores da religião islâmica em nome da ordem e segurança pública em seus países, propagando-se e falsamente legitimando a proliferação dos sentimentos de medo e intolerância pelo mundo.

Mais especificamente, para exemplificar a existência do preconceito e intolerância religiosa voltados aos muçulmanos, citou-se neste escrito a elaboração de leis internas advindas de países ocidentais que visam a proibição do uso dos véus islâmicos, entre outros símbolos que caracterizam a religião islâmica, pelos seus seguidores em locais públicos. Situação essa que, além de contrariar os instrumentos de proteção dos direitos humanos, vai de encontro às regras de direito internacional dos direitos humanos que protegem especificamente as minorias, neste caso, uma minoria religiosa.

Nesse sentido, entendeu-se que os Estados acabaram por disseminar certa intolerância para com os muçulmanos, mesmo diante de regras devidamente positivadas que permitam livremente ao homem decidir a religião e expressá-la conforme as suas crenças, sem a intromissão do Estado. Logo, diante desse contexto, concluiu-se que existe, sim um direito de liberdade negativa que deveria ser assegurado pelo Estado, muito embora a conduta de diversas nações, particularmente a partir do 11 de setembro, fossem em sentido contrário, terminando por violar o direito à liberdade de religião e a necessidade de tolerância para com outras culturas.

Assim sendo, na segunda parte deste texto, adentrou-se em um dos principais e mais complexos desafios dos direitos humanos da ordem internacional contemporânea, pois tratou-se da própria fundamentação dos direitos humanos, a qual serve como base para advogar-se em prol da preservação destes direitos, seja por serem considerados inerentes a qualquer homem (universalismo), seja por serem analisados a partir do olhar de uma única cultura (relativismo). Apesar disso, nesse ponto, asseverou-se justamente que para superar os atos intolerantes e de violação ao 
direito da liberdade religiosa, não seria factível ter como base essas duas correntes, haja vista a fragilidade do monoculturalismo forjado por ambas.

Nesse contexto, seria necessário encontrar outro aporte para realizar as conexões necessárias para tutelarem-se as muçulmanas diante da conjuntura atual, efetivando o seu direito de liberdade religiosa e afugentando a intolerância. Por conseguinte, considerou-se ser imprescindível que as diferentes culturas sejam consideradas para a aplicação e fundamentação dos direitos dos indivíduos, em que pese ela não possa ser unilateral, desconsiderando o seu entorno e os ganhos que ela poderia obter ao dialogar com seus pares.

Por isso, concluiu-se que não há como falar em garantias à dignidade humana e proteção dos direitos humanos fundamentais, sem a observância do elemento cultural - religião, costumes, idioma, vestimentas - carregado pelo indivíduo. Entretanto, tampouco entendeu-se igualmente não ser possível vedar o contato com outras culturas para que não se esvaziasse a própria humanidade, sendo o diálogo intercultural necessário não só para instituir o respeito e a tolerância para com "o diferente" (aos olhos ocidentais), como também para a própria transformação e redefinição dos direitos humanos em si ao valorizar e reconhecer o próximo (pois também um homem) na sua própria diferença, sem subtrair direitos de uns - minorias em prol de outros - maioria - na sociedade global.

Então, tem-se que combinando o multiculturalismo - valorizando o diálogo multicultural entre os povos - e a tolerância cultural - reconhecimento e respeito ao outro - os propósitos do Direito Internacional dos Direitos Humanos podem ser alcançados com êxito. Afinal, a possibilidade de fundamentação dos direitos humanos, principalmente a liberdade religiosa dos seguidores do islamismo, pelo viés do multiculturalismo, se apresenta mais dinâmico e por isso, mais completo, englobando a proteção do que é essencial ao indivíduo, bem como a sua essencialidade na vida e no mundo. 


\section{REFERÊNCIAS}

ALVES, J. A. Lindgren. Os direitos humanos na pós-modernidade. São Paulo: Perspectiva, 2005.

BATISTA, Gustavo Cristóvão de Oliveira. A (in)compreensão da liberdade religiosa na jurisdição brasileira: uma necessária abertura do processo interpretativo em uma sociedade pós-metafísica / Gustavo Cristóvão de Oliveira Batista, 2010.

BATISTA, Gustavo Cristóvão de Oliveira. Pluralismo e liberdade religiosa: por uma construção coletiva aberta. Revista Negócios e Talentos, n 14, 2015/1.

BOAVENTURA, de Sousa Santos. Reconhecer para libertar: os caminhos do cosmopolitismo multicultural. Rio de Janeiro: Civilização Brasileira, 2003.

BOBBIO, Noberto. A era dos direitos. (Tradução de: L'età dei Diritti). Tradução por Carlos Nelson Coutinho. Apresentação de Celso Lafer Nova ed. Rio de Janeiro: Elsevier, 2004.

BRASIL. Decreto ${ }^{\circ}$ 592, de 6 de julho de 1992. Atos Internacionais. Pacto Internacional sobre Direitos Civis e Políticos. Disponível em: <http://www.planalto.gov.br/ccivil_03/decreto/1990-1994/d0592.htm.>. Acesso em: 10 set. 2019.

BRASIL. Decreto $n^{\circ} 7.030$, de 14 de dezembro de 2009. Promulga a Convenção de Viena sobre o Direito dos Tratados, concluída em 23 de maio de 1969, com reserva aos Artigos 25 e 66. Disponível em: <http://www.planalto.gov.br/ccivil_03/_ato20072010/2009/decreto/d7030.htm>. Acesso em: 10 set. 2019.

CARDOSO, Clodoaldo Meneguello. Tolerância e seus limites: um olhar latinoamericano sobre a diversidade e desigualdade. Disponível em:

<http://textos.pucp.edu.pe/pdf/2091.pdf>. Acesso em: 10 set. 2019.

CARDOSO. Tatiana de Almeida F.R. A proibição do uso da burca e o universalismo dos direitos humanos. Emblemas - Revista do departamento de história e ciências sociais - UFG/CAC. v. 10, n. 2 (2013): Dossiê Gênero, sexualidade e direitos humanos.

COLLARES, Valdeli Coelho. O véu depois do 11 se setembro - A identidade e o direito das mulheres islâmicas. Revista Aurora, ano V, número 9, ISSN: 1982-8004, 
dezembro de 2011. Disponível em:

<http://www2.marilia.unesp.br/revistas/índex.php/aurora/>. Acesso em: 10 set. 2019.

COMPARATO, Fábio Konder. A Afirmação histórica dos Direitos Humanos. $7^{\mathrm{a}}$ ed. rev. e atual. - São Paulo: Saraiva, 2010.

CONVENÇÃO EUROPEIA DOS DIREITOS HUMANOS, de 4 de novembro de 1950. Disponível em: <http://www.echr.coe.int/Documents/Convention_POR.pdf>. Acesso em: 09 set. 2019.

DONNELLY, Jack. Universal Human Rights in Theory and Practice. 3rd ed. 3rd ed. ISBN: 9780801450952. Ithaca: Cornell University Press, 2013.

EBERHARD, Christoph. Direitos humanos e diálogo intercultural: uma perspectiva antropológica. In: BALDI, César Augusto. Direitos humanos na sociedade

Cosmopolita. Rio de Janeiro: Renovar, 2004.

FERREIRA, Pinto. Curso de Direito Constitucional. 9a ed. São Paulo: Saraiva, 1998.

FISCHMANN, Roseli. Estado laico, educação, tolerância e cidadania: para uma análise da concordata. São Paulo: Factash Editora, 2012.

FRANÇA, Jefferson Luiz de. Kant e a Concepção Contemporânea de Direitos Humanos: Conquistas e Desafios à Teoria Geral dos Direitos Humanos. Revista

Direitos Humanos e Democracia, Editora Unijuí, ano 4, n. 7, jan./jun., 2016.

Disponível em:

<https://www.revistas.unijui.edu.br/index.php/direitoshumanosedemocracia>. Acesso em: 30 ago. 2019.

GAARDER, Jostein. O livro das Religiões. São Paulo: Companhia das Letras, 2000.

GONÇALVES, Antônio Baptista. A relação da intolerância religiosa com os direitos humanos. 2011.

GUIMARÃES, Débora Soares. Análise da importância da concepção universal dos direitos humanos e da sua justicialização ante o multiculturalismo. In: Revista CEJ/ Conselho da Justiça Federal, Centro de Estudos Judiciários. Brasília, n. 47. v. 13, out./dez. 2009.

HUNTINGTON, Samuel P. O Choque de Civilizações e a Recomposição da Ordem Mundial. Rio de Janeiro: Editora Objetiva Ltda, 1997.

JORNAL EXTRA. Candidatura de Trump: Propaganda-para autoritários. Jornal Extra, Rio de Janeiro, 29 out. 2016. Disponível em

<http://extra.globo.com/noticias/mundo/artigo-mera-candidatura-de-trump-propagandapara-autoritarios-20381253.html>. Acesso em: 18 abr. 2019.

MIRANDA, Jorge. Manual de Direito Constitucional. 3ed., t. IV, Coimbra editora, 2000.

MIRANDA, Jorge; MEDEIROS. Rui Medeiros. Constituição Portuguesa Anotada. 
Tomo I, 2009.

MONTIEL, Edgar. A nova ordem simbólica: a diversidade cultural na era da globalização. In: SIDECUM, Antônio (Org.). Alteridade e multiculturalismo. Rio Grande do Sul: Unijuí, 2003.

ONU. Assembléia Geral das Nações Unidas. Pacto Internacional dos Direitos Civis e Políticos. Adotado pela Resolução n. 2.200 A (XXI), em 16 de dezembro de 1966.

ONU. Carta das Nações Unidas. Estabeleceu as Nações Unidas. Disponível em: <http://unicrio.org.br/img/CartadaONU_Versolnternet.pdf>. Acesso em: 12 ago. 2019.

ONU. Declaração de Viena e Plano de Ação. 1993. Disponível em: <http://www.onumulheres.org.br/wpcontent/uploads/2013/03/declaracao_viena.pdf>. Acesso em: 27 abr. 2019.

ONU. Declaração Universal dos Direitos Humanos, de 10 de dezembro de 1948. Disponível em: <http://www.dudh.org.br/wp-content/uploads/2014/12/dudh.pdf $\geq$. Acesso em: 20 ago. 2019.

ORGANIZAÇÃO DAS NAÇÕES UNIDAS (ONU). Declaração de Viena e Plano de Ação. 1993. Conferência Mundial sobre Direitos Humanos. Disponível em: <https://www.oas.org/dil/port/1993\%20Declara\%C3\%A7\%C3\%A30\%20e\%20Programa \%20de\%20Ac\%C3\%A7\%C3\%A30\%20adoptado\%20pela\%20Confer\%C3\%AAncia\%20 Mundial\%20de $\% 20$ Viena\%20sobre\%20Direitos\%20Humanos\%20em $\% 20$ junho\%20de \%201993.pdf>. Acesso em: 12 ago. 2019.

ORGANIZAÇÃO DAS NAÇÕES UNIDAS (ONU). Status de tratado: Convenção Americana de Direitos Humanos, 1993. Disponível em:

$<$ https://treaties.un.org/pages/showdetails.aspx?objid $=08000002800 f 10 \mathrm{e} 1>$ Acesso em: 14 ago. 2019.

PEIXOTO, Érica de Souza Pessanha. Universalismo e Relativismo Cultural. Revista da Faculdade de Direito de Campos, Ano VIII, N 10, jun./ 2007.

PIOVESAN, Flávia. Direitos Humanos e Justiça Internacional: Um estudo comparativo dos sistemas regionais europeu, interamericano e africano. 3ed. ver., ampl. e atual. São Paulo: Saraiva, 2012.

POTTUMATI, Eduardo Carlos. Direitos humanos, universalismo e relativismo: em busca de diálogo e novos paradigmas. Argumenta Journal Law, 2014. Disponível em: $<$ http://seer.uenp.edu.br/index.php/argumenta/article/view/450/pdf_55>. Acesso em: 11 set. 2019.

REZENDE, Thomaz. Infográfico: Muçulmanos na Europa de 1990 a 2010. Disponível em: <http://veja.abril.com.br/multimidia/infograficos/imigrantes-e-muculmanos-naeuropa-de-1990-a-2010>. Acesso em: 30 ago. 2019.

SANTOS, Boaventura de Sousa. Por uma concepção multicultural de direitos humanos. In: BALDI, César Augusto. Direitos humanos na sociedade Cosmopolita. Rio de Janeiro: Renovar, 2004. 
SANTOS, Boaventura de Sousa. Reconhecer para libertar: os caminhos do cosmopolitismo multicultural. Rio de Janeiro: Civilização Brasileira, 2003.

SCALCO, Pedro. Uma breve análise da fundamentação dos direitos humanos: universalismo e/ou relativismo cultural. "O dever de ter respeito pelas pessoas têm valor em si mesmas, extrai suas manifestações concretas das práticas sócias". Revista dos Tribunais, Ano 98, vol. 890, dez. 2009.

SILVA, Marília Ferreira da; PEREIRA, Erick Wilson. Universalismo x Relativismo: um entrave cultural ao projeto de humanização social. Disponível em: <http://www.publicadireito.com.br/artigos/?cod=74105d373a71b517>. Acesso em: 03 ago. 2019.

SORIANO, Aldir Guedes. Liberdade Religiosa no Direito Constitucional e Internacional. 1ed. São Paulo: Editora Juarez de Oliveira, 2002.

SQUEFF, Tatiana de A. F. R. Cardoso; TEIXEIRA, Bruno Marques. As Diversas Possibilidades de Fundamentação dos Direitos Humanos: entre o(s) universalismo(s) e o(s) relativismo(s). In: SILVEIRA, Vladimir Oliveira da; LOPES, Ana Maria D’Ávila;

SPOSATO, Karyna Batista. (Orgs.). Direito internacional dos Direitos Humanos. Florianópolis: Conpedi/UFS, 2015.

SQUEFF, Tatiana de Almeida Freitas Rodrigues Cardoso. Estado plurinacional: a proteção do indígena em torno da construção da hidrelétrica de Belo Monte. Curitiba: Juruá, 2016.

TAVARES, Felipe Cavaliere. Direitos Humanos e Diversidade Cultural: A Dignidade Humana entre o Universalismo e o Relativismo. Conpedi/UFS, 2015.

TAYLOR, Charles. Multiculturalismo: examinando a política de reconhecimento. Núcleo de Direitos Humanos, Unisinos, dez./2014.

UNESCO. Declaração Universal sobre a Diversidade Cultural de 2002.Disponível em: < http://unesdoc.unesco.org/images/0012/001271/127160por.pdf>. Acesso em: 15 ago. 2019.

VIEIRA, Liszt. Cidadania e globalização. Rio de Janeiro: Editora Record, 2000.

ZARKA, Yves Charles. Difícil Tolerância: a coexistência de culturas em regimes democráticos. São Leopoldo: Editora Unisinos, 2013. 